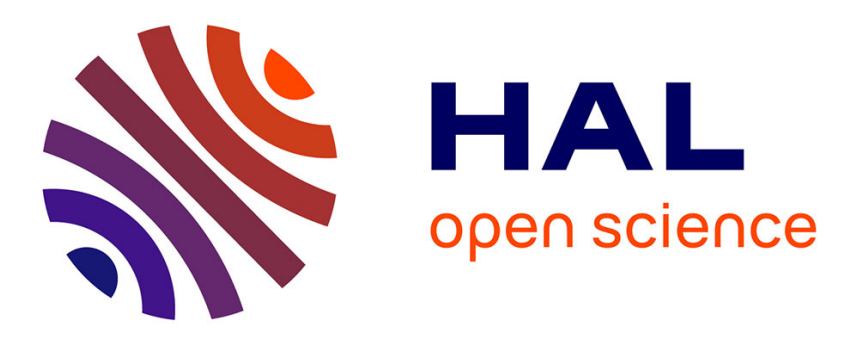

\title{
Archaeal overdominance close to life-limiting conditions in geothermally influenced hypersaline lakes at the Danakil Depression, Ethiopia
}

Jodie Belilla, Miguel Iniesto, David Moreira, Karim Benzerara, José María López-garcía, Ana López-archilla, Guillaume Reboul, Philippe Deschamps, Emmanuelle Gérard, Purificación López-garcía

\section{To cite this version:}

Jodie Belilla, Miguel Iniesto, David Moreira, Karim Benzerara, José María López-garcía, et al.. Archaeal overdominance close to life-limiting conditions in geothermally influenced hypersaline lakes at the Danakil Depression, Ethiopia. Environmental Microbiology, 2021, 10.1111/1462-2920.15771 . hal-03384106

\author{
HAL Id: hal-03384106 \\ https://hal.science/hal-03384106
}

Submitted on 18 Oct 2021

HAL is a multi-disciplinary open access archive for the deposit and dissemination of scientific research documents, whether they are published or not. The documents may come from teaching and research institutions in France or abroad, or from public or private research centers.
L'archive ouverte pluridisciplinaire HAL, est destinée au dépôt et à la diffusion de documents scientifiques de niveau recherche, publiés ou non, émanant des établissements d'enseignement et de recherche français ou étrangers, des laboratoires publics ou privés. 
Archaeal overdominance close to life-limiting conditions in geothermally influenced hypersaline lakes at the Danakil Depression, Ethiopia

5 Jodie Belilla ${ }^{*}$, Miguel Iniesto ${ }^{1 *}$, David Moreira1, Karim Benzerara², José María López-García ${ }^{3}$, Ana I. López-Archilla ${ }^{4}$, Guillaume Reboul', Philippe Deschamps ${ }^{1}$, Emmanuelle Gérard ${ }^{5}$ and Purificación López-García ${ }^{1}$

1 Ecologie Systématique Evolution, CNRS, Université Paris-Sud, Université Paris-Saclay, AgroParisTech, Orsay, France.

2 Institut de Minéralogie, de Physique des Matériaux et de Cosmochimie, CNRS, Sorbonne Université, Muséum National d'Histoire Naturelle, Paris, France.

${ }^{3}$ Instituto Geológico y Minero de España, IGME_CSIC, Palma de Mallorca, Spain

${ }^{4}$ Departamento de Ecología, Universidad Autónoma de Madrid, Madrid, Spain

$15{ }^{5}$ Institut de Physique du Globe de Paris, Paris, France

* These authors contributed equally

For correspondence: puri.lopez@universite-paris-saclay.fr 
The North of the Danakil Depression is an active tectonic, seismic and volcanic area that hosts several polyextreme environments combining hypersalinity, low $\mathrm{pH}$ and high temperature. While the most extreme brines at and around the protovolcanic dome of Dallol do not host active life, less extreme, hypersaline systems harbor diverse microbial communities. We have discovered several lakes in this area with a physicochemistry bridging the gap between those conditions. They host lower-diversity microbial communities overwhelmingly dominated by archaea ( $99 \%$ of $16 \mathrm{~S}$ rRNA gene amplicon sequences), notably Halobacteriota and Nanohaloarchaeota. We could observe diverse morphotypes and tiny epibionts attach to small cells, but also silica-rich rounded biomorphs of similar size to small cells that might be confounded with microorganisms. 


\section{S ummary}

40 The Dallol protovolcanic area on the Danakil Depression (Afar region, E thiopia) exhibits unique hydrothermal manifestations in hypersaline context, yielding varied polyextreme physicochemical conditions. P revious studies identified a wide archaeal diversity in less extreme brines but failed to identify microorganisms thriving in either high-chaotropicity, low-wateractivity brines or hyperacidic-hypersaline $\mathrm{Na}$-Fe-rich brines. Recently, we accessed several small lakes under intense degassing activity adjacent to the Round Mountain, west to the Dallol dome (Western Canyon Lakes; WCL 1-5). They exhibited intermediate parameter combinations ( $\mathrm{pH} \sim 5,34-41 \% \mathrm{NaCl}$-dominated salts with relatively high levels of chaotropic $\mathrm{Mg}$-Ca salts) that should allow to better constrain life limits. These lakes were overwhelmingly dominated by Archaea, encompassing up to $99 \%$ of prokaryotic $16 \mathrm{~S}$ rRNA gene amplicon sequences in metabarcoding studies. The majority belonged to Halobacteriota and Nanohaloarchaeota, the latter representing up to half of prokaryotic sequences. Optical and epifluorescence microscopy showed active cells in natural samples and diverse morphotypes in enrichment cultures. S canning electron micros copy coupled with energy-dis pers ive x-ray spectros copy revealed tiny cells (200-300 $\mathrm{nm}$ diameter) epibiotically associated with somewhat larger cells $(0.6-1 \mu \mathrm{m})$ but also the presence of silica-dominated precipitates of similar size and shape, highlighting the difficulty of dis tinguishing microbes from mineral biomorphs in this kind of low-biomass systems.

Keywords: hypersaline, chaotropicity, water-activity, biomorphs, polyextreme environments, Nanohaloarchaeota, habitability 
Page 4 of 39 


\section{Introduction}

Environments challenging for life may display several physical or chemical so-called extreme conditions (Harrison et al., 2013; Merino et al., 2019). The limits of life face to polyextreme conditions are less well defined than those to specific parameters such as temperature, $\mathrm{pH}$ or salinity, especially in cases where particular combinations of extreme parameter values are rare. Thus, although biotopes combining high salinity and high $\mathrm{pH}$ are relatively common and haloalkaliphiles have been studied for some time (Mesbah and Wiegel, 2012; Sorokin et al., 2015), environments displaying a combination of low pH and high salinity are scarce around the world, limiting the investigation of the microbial communities potentially inhabiting them. Microbial communities have been described in a series of Western Australian lakes that display $\mathrm{pH}$ values as low as 1.5 and salinity concentrations as high as $32 \%$ (weight/volume) under a regime of high seasonal variability (Mormile et al., 2009; Johnson et al., 2015; Zaikova et al., 2018). Highly acidic brines ( $\mathrm{pH} \mathrm{1-4.7)} \mathrm{in} \mathrm{the} \mathrm{Northern} \mathrm{Chilean} \mathrm{Andes} \mathrm{with} \mathrm{relatively} \mathrm{high}$ concentrations of sodium, magnesium and chlorine harbor a limited diversity of microbial lineages (Escudero et al., 2013). High salinity is challenging, largely due to a reduced water activity (Stevenson et al., 2015), which approaches the limits known for life in these acid brines in Chile and Australia (Benison et al., 2021). Moreover, the chemical nature of salts imposes additional constraints. $\mathrm{NaCl}$ brines are thermodynamically much more permissive for life than brines enriched in more chaotropic salts, typically those containing magnesium and/or calcium (Hallsworth et al., 2007; Lee et al., 2018). These conditions can also be found in deep-sea brines. For instance, the so-called 'Lakes' Kryos and Hephaestus found at ca. 3,500 m depth in the Mediterranean Sea, are considered among the most chaotropic and low water-activity systems that harbor microbial life (Yakimov et al., 2015; La Cono et al., 2019). 
Recently, we studied the presence and diversity of autochthonous microbial communities along polyextreme gradients exhibiting rare combinations of hypersalinity ( 20 to $>50 \%)$, low $\mathrm{pH}$ ( $\sim$ to 6.0 ) and high temperature $\left(25-110^{\circ} \mathrm{C}\right)$ in the Dallol geothermal area (Afar region, Ethiopia) (Belilla et al., 2019). Dallol is a proto-volcanic uplifted salt dome displaying intense degassing and hydrothermal activity in the North of the Danakil Depression ( 120 m below-sea-level), which extends over a $200 \mathrm{~km}$-long basin following the Afar rift at the north junction between three main tectonic plates (Varet, 2018; López-García et al., 2020). Being one of the hottest regions in the planet (Pedgley, 1967), the evaporation rate is high. Consequently, when the tectonic and volcanic activity closed the entry of the Red Sea waters in the area during the Pleistocene, seawater evaporation led to the deposition of the $\sim 2 \mathrm{~km}$ thick salt layer that covers the depression nowadays (Bonatti et al., 1971; López-García et al., 2020). Today, meteoric waters infiltrating mostly from the nearby high Ethiopian plateau $(>2,500 \mathrm{~m})$ interact with the underlying geothermal reservoir $\left(280-370^{\circ} \mathrm{C}\right)$ (Darrah et al., 2013; Franzson et al., 2015), forming highly saline fluids as they traverse the evaporite deposits. This results in diverse hydrothermal manifestations on top and around the dome of Dallol with unique combinations of polyextreme conditions and salt chemistries (Holwerda and Hutchinson, 1968; Franzson et al., 2015; Warren, 2015; Varet, 2018; Belilla et al., 2019; Cavalazzi et al., 2019; Kotopoulou et al., 2019). We were able to reliably detect active microbial communities in a salt-karst cave reservoir in the canyons of the Dallol dome west side and in the salt plain around the dome as well as in the hydrothermally-influenced hypersaline Lake Assale (or Karum), some $30 \mathrm{~km}$ to the south within the depression. These ecosystems, being $\mathrm{NaCl}$-dominated with $~ 35 \%$ salinity, moderate temperature $\left(\sim 30^{\circ} \mathrm{C}\right)$ and $\mathrm{pH}(\sim 4-6)$, were largely enriched $(>85 \%)$ in highly diverse archaea, notably Halobacteriota and Nanohaloarchaeota (Belilla et al., 2019). By contrast, various lines of evidence (cultures, molecular metabarcoding, fluorescence-activated cell-sorting (FACS) and 
microscopy) failed to unambiguously identify microbial life thriving in two other types of chemical environments in the Dallol area despite the presence of liquid water. One encompassed the Black and Yellow (Gaet'ale) lakes and associated ponds at the southwest and southeast of the dome, respectively, characterized by lower $\mathrm{pH}(\sim 1.8-3)$ and higher temperatures $\left(40-70^{\circ} \mathrm{C}\right)$ and salts (> 50\% weight/volume) enriched in $\mathrm{Mg}{ }^{2+}$ and $\mathrm{Ca}{ }^{2+}$. The other corresponded to the highly acidic $(\mathrm{pH}<0)$, hypersaline $(37-42 \%)$ and sometimes hot $\left(\sim 30-108^{\circ} \mathrm{C}\right)$ colorful ponds on top of the dome, which were enriched in $\mathrm{Na}^{+}, \mathrm{Fe}^{2+/ 3+}$ and $\mathrm{Cl}^{-}$. Accordingly, we identified two major barriers to life related to high chaotropicity (Black and Yellow lakes) and the combination of extreme hyperacidity and high salinity with, potentially, the presence of sterilizing chemical compounds (Belilla et al., 2019). However, the significant gap between the physicochemical parameter values of the less and the most polyextreme samples prevented setting a more precise limit of life along this polyextreme gradient.

In our last expedition to the area (January 2019), we sampled a series of small lakes that we named the Western Canyon Lakes (WCL) due to their close location to small salt canyons from the Round Mountain west to Dallol in the Danakil Depression. These relatively stable lakes influenced by hydrothermal activity with intense degassing (bubbling) displayed peculiar chemistry combined with $\mathrm{pH}$, salinity, chaotropicity and water activity values that made them approach further the conditions limiting for life. Here, we applied environmental 16S/18S rRNA gene metabarcoding and diverse observational approaches to explore these systems.

\section{Experimental procedures}

\section{Sampling and in situ measurement of physicochemical parameters}

Samples were collected from the Western Canyon Lakes (WCL-1 to 5) during a field trip to the Danakil depression in January 2019. These lakes are located at the base of the Round 
Mountain, to the west of the Dallol dome (Fig.1). We also collected water samples from a previously studied Dallol salt canyon cave $(9 \mathrm{Gt})$ as well as from the middle of the Lake Assale or Karum (sample 9Ass-Isl) and several lifeless hyperacidic hydrothermal brines at the Dallol dome (9DA samples) and the Black (9BL) and Yellow (Gaet'ale; 9YL) lakes (Tables 1 and S1). For comparison, we included in the present study data from Belilla et al. (2019) obtained from samples collected in the Dallol area where autochthonous microbial communities were thriving (Table S1). All sampling points and mapping data were georeferenced using a Trimble ${ }^{\circledast}$ handheld GPS (JunoSB series) equipped with Environmental Systems Research Institute software $\operatorname{ArcPad}^{\oplus}$ 10. Physicochemical parameters were measured in situ with a YSI Professional Series Plus multiparameter probe for temperatures up to $70{ }^{\circ} \mathrm{C}$ and with a Hanna HI93530 temperature probe (working range $-200 / 1,000{ }^{\circ} \mathrm{C}$ ) and a Hanna $\mathrm{HI} 991001 \mathrm{pH}$ probe (working range $-5 / 105^{\circ} \mathrm{C} ; \mathrm{pH}$ range $-2.00 / 16.00$ ) at higher temperatures. Salinity was measured in situ with a refractometer on 1/10 dilutions in MilliQ water. Water samples ( 5 to 14 I for Lake Assale and the Western Canyon Lakes, 25 I for the cave pond in the Dallol salt canyons) were sequentially filtered through $30-\mu \mathrm{m}$ and $0.22-\mu \mathrm{m}$ pore-diameter Nucleopore filters (Whatman, Maidstone, UK). The $<0.22-\mu \mathrm{m}$ filtrates were collected for chemical analyses in $50-\mathrm{ml}$ glass bottles filled to the top and sealed with rubber stoppers to prevent further oxidation of fluids. Filters retaining $0.2-30 \mu \mathrm{m}$ particles were fixed with absolute ethanol (>80\% final concentration) in 2-ml cryotubes. Back in the laboratory, ethanol-fixed samples were stored at $\quad-20^{\circ} \mathrm{C}$ until use.

The chemical composition of the solutions was analyzed using $0.2-\mu \mathrm{m}$ prefiltered brine samples. Major and trace elements were analyzed at the SIDI Service (Servicio Interdepartamental de Investigación, Universidad Autónoma de Madrid, Spain) by total reflection X-ray fluorescence 
with a TXRF-8030c FEl spectrometer and inductively coupled plasma-mass spectrometry using a Perkin-Elmer NexION 300XX instrument (Table S2). Several anions and cations (SO $\mathrm{Br}^{-}, \mathrm{F}^{-}, \mathrm{Na}^{+}, \mathrm{K}^{+}, \mathrm{Mg}^{2+}, \mathrm{Ca}^{2+}$ ) were also analyzed at the Unidad de Técnicas Geológicas (Universidad Complutense de Madrid, Spain) by ionic chromatography using a Dionex DX-500 apparatus (Table S3). Organic molecules were characterized at SIDI using a Varian HPLCdiode array detector/FL/LS liquid chromatograph (Table S4). Salinity (weight/volume, expressed in percentage throughout the manuscript) was also experimentally measured in triplicates in the laboratory by weighting the total solids after heat-drying $1 \mathrm{ml}$ aliquots at $120^{\circ} \mathrm{C}$ for at least $24 \mathrm{~h}$. Water activity was measured at the Muséum National d'Histoire Naturelle at room temperature $\left(25^{\circ} \mathrm{C}\right)$ on $10-\mathrm{ml}$ unfiltered aliquots using a HC2-AW probe and HP23-AW-A indicator (Rotronic AG, Bassersdorf, Switzerland) calibrated at $23^{\circ} \mathrm{C}$ using the AwQuick acquisition mode (error per measure 0.0027$)$. Chaotropicity was experimentally determined from the temperature of gelation of ultrapure gelatin (for Ca-rich samples) and agar (rest of samples) using a spectrometric assay, as previously described (Cray et al., 2013; Belilla et al., 2019). Principal component analyses (PCA) of samples, chemical and physicochemical parameters (Fig. 2) were carried out using the R-software ( $R$ Development Core Team, 2017) packages FactoMineR (Lê et al., 2008) and factoextra (Kassambara and Mundt, 2017).

\section{DNA purification, 16S/18S rRNA gene amplification and sequencing}

DNA was purified from $0.2 \mu \mathrm{m}$ filter-retained biomass using the Power Soil DNA Isolation Kit (MoBio, Carlsbad, CA, USA) under a UV-irradiated Erlab CaptairBio DNA/RNA PCR Workstation. Samples were let rehydrate for at least $2 \mathrm{~h}$ at $4^{\circ} \mathrm{C}$ in the kit resuspension buffer. DNA was resuspended in $10 \mathrm{mM}$ Tris- $\mathrm{HCl}, \mathrm{pH} 8.0$ and stored at $-20^{\circ} \mathrm{C}$. Bacterial and archaeal 16S rRNA gene fragments of approximatively 290 bp encompassing the V4 hypervariable 
region were PCR-amplified using U515F (5'-GTGCCAGCMGCCGCGGTAA) and U806R (5'GGACTACVSGGGTATCTAAT) primers. PCR reactions were conducted in $25 \mu \mathrm{l}$, using $1.5 \mathrm{mM}$ $\mathrm{MgCl}_{2}, 0.2 \mathrm{mM}$ of each dNTP (PCR Nucleotide Mix, Promega), $0.1 \mu \mathrm{M}$ of each primer, $1 \mu \mathrm{l}$ of purified DNA and $1 \mathrm{U}$ of the hot-start Taq Platinum polymerase (Invitrogen, Carlsbad, CA, USA). Amplification reactions proceeded for 35 cycles $\left(94^{\circ} \mathrm{C}\right.$ for $15 \mathrm{~s}, 50$ to $55^{\circ} \mathrm{C}$ for $30 \mathrm{~s}$ and $72^{\circ} \mathrm{C}$ for $90 \mathrm{~s})$, after a 2 min-denaturation step at $94^{\circ} \mathrm{C}$ and before a final extension at $72^{\circ} \mathrm{C}$ for $10 \mathrm{~min}$. All WCL, 9Gt and 9Ass-9Isl samples yielded amplicons in direct PCR reactions; all control reactions without template DNA were negative. Amplicons were visualized after gel electrophoresis and ultrasensitive GelRed ${ }^{\circledR}$ nucleic acid gel stain (Biotium, Fremont, CA, USA) on a UV-light transilluminator. Eukaryotic $18 \mathrm{~S}$ rRNA gene fragments including the V4 hypervariable region were amplified using primers EK-565F (5'-GCAGTTAAAAAGCTCGTAGT) and 18S-EUK-1134-R-UNonMet (5'-TTTAAGTTCAGCCTTGCG). In the case of WCLs, seminested PCRs were carried out from amplicons generated using the forward eukaryotic primer EK-82F (5'-GAAACTGCGAATGGCTC). Primers were tagged with different Molecular IDentifiers (MIDs) to allow multiplexing and subsequent sequence sorting. Amplicons from at least 5 independent PCR products for each sample were pooled together and then purified using the QIAquick PCR purification kit (Qiagen, Hilden, Germany). DNA concentrations were measured using Qubit TM dsDNA HS assays (Invitrogen). Equivalent amounts of amplicons were multiplexed and sequenced using paired-end (2x300 bp) MiSeq Illumina technology (Eurofins Genomics, Ebersberg, Germany). Illumina sequences have been deposited in the GenBank Short Read Archive with BioProject number PRJNA541281 (samples SAMN19575669 to SAMN19575675). 
Raw sequences were processed and analyzed using QIIME2 (Estaki et al., 2020). Primers and MIDs were trimmed with cutadapt (Martin, 2011). Demultiplexing was performed using the "cutadapt demux-paired" function to look for MIDs at the beginning of sequences and properly

210 attribute them to samples. Paired-end sequences were denoised, dereplicated and chimerafiltered using the DADA2 algorithm version 2018.2.6 (dada2 denoised-paired function) (Callahan et al., 2016). Reads were trimmed to retain only high-quality sequences based on quality plots. Amplicon sequence variants (ASVs) were assigned to phylogenetic taxa using the SILVA reference database (release 138) (Quast et al., 2013) prior to reconstructing relative abundance histograms. We followed the taxonomy used by SILVA but preferred the term Halobacteriota (and not Halobacterota) for the phylum encompassing classical haloarchaea based on the name of the first described genus, Halobacterium, as per the GTDB (https://gtdb.ecogenomic.org). Diversity (Simpson), richness (Chao1) and evenness indices were determined using R-package Vegan (Oksanen et al., 2011). In addition, we placed the newly identified archaeal and bacterial sequences in reference phylogenetic trees. To do so, we enriched previously generated reference alignments (Belilla et al., 2019) using MAFFT-linsi v7.38 (Katoh and Standley, 2013). These contained near full-length archaeal and bacterial 16S rRNA gene reference sequences from major identified taxa, the closest blast-hits to our sequences and near-full 16S rRNA gene Sanger sequences previously obtained from Lake Assale, the cave and the salt plain (Belilla et al., 2019). Poorly aligned regions were removed using TrimAl (Capella-Gutierrez et al., 2009). Maximum likelihood (ML) phylogenetic trees were constructed with IQ-TREE (Nguyen et al., 2015) using the GTR model of sequence evolution with a gamma law and taking into account invariable sites $(\mathrm{GTR}+\mathrm{G}+\mathrm{l})$. Node support was estimated by ultrafast bootstrapping as implemented in IQ-TREE. Our shorter sequences were then added to the reference alignment using MAFFT (accurate -linsi 'addfragments' option). 
This final alignment was split in two files (references and ASVs) before using the EPA-ng tool (https://github.com/Pbdas/epa-ng) to place ASVs in the reference trees reconstructed with IQTREE. The jplace files generated by EPA-ng were transformed into newick tree files (provided as supplementary material) with the genesis library ( https://github.com/lczech/genesis ). Tree visualization and the addition of rings were done with GraphLan (Asnicar et al., 2015). In addition, we reconstructed more specific ML phylogenetic trees (IQ-TREE, as above) for representative subsets of amplicon sequences belonging to the Halobacteriota and the Nanohaloarchaeota.

SEM analyses were carried out on liquid brine samples deposited onto $0.1 \mu \mathrm{m}$ pore-diameter filters (Whatman) by vacuum aspiration and briefly rinsed with $0.1-\mu \mathrm{m}$ filtered and autoclaved MilliQ water. Filters were vacuum-dried and stocked within dry atmosphere until they were sputtered with carbon for SEM observations. SEM analyses were performed using a Zeiss ultra55 field emission gun (FEG) SEM. Secondary electron (SE2) images were acquired using an In Lens detector at an accelerating voltage of $2.0 \mathrm{kV}$ and a working distance of $\sim 3.0 \mathrm{~mm}$. Backscattered electron images were acquired for chemical mapping using an angle selective backscattered (AsB) detector at an accelerating voltage of $15 \mathrm{kV}$ and a working distance of $\mathrm{mm}$. Elemental maps were generated from hyperspectral images (HyperMap) by energy dispersive X-ray spectrometry (EDXS) using an EDS QUANTAX detector. EDXS data were analyzed using the ESPRIT software package (Bruker). 
Fluorescence in situ hybridization (FISH) was carried out on cells freshly fixed in $2 \%$ 255 formaldehyde (BioValley) for $2 \mathrm{~h}$ at $4^{\circ} \mathrm{C}$, and then washed and dehydrated in ethanol dilutions of increasing concentration (50-80-100\%). Hybridization with archaea-specific probes (5 ng/ $\mu \mathrm{l}) \mathrm{S}$ D-Arch-0915-a-A-20 (ARC915-CY3; 5'-GTGCTCCCCCGCCAATTCCT-3') and S-K-Eury0498-a-A-14 (EURY498-FITC-; 5'-CTTGCCCRGCCCTT-3') was carried out at $46^{\circ} \mathrm{C}$ for $2 \mathrm{~h}$ in $0.9 \mathrm{M} \mathrm{NaCl}, 20 \mathrm{mM}$ Tris- $\mathrm{HCl}$ pH 8, 0.01\% SDS containing 35\% formamide. Samples were then washed for $15 \mathrm{~min}$ at $48^{\circ} \mathrm{C}$ in $20 \mathrm{mM}$ Tris pH $8.5 \mathrm{mM}$ EDTA, $0.01 \%$ SDS, $0.084 \mathrm{mM} \mathrm{NaCl}$, soaked in cold water for a few seconds and air dried. DNA in samples was stained by incubation with DAPI (1 $\mu \mathrm{g} / \mathrm{ml}$ [Sigma]) for $1 \mathrm{~min}$, washed for a few seconds in cold water and left to dry. Hybridized cells, covered by Citifluor AF3 (Agar Scientific), were examined under a Zeiss Axioplan 2 Imaging epifluorescence microscope using the following specific filters: U-MNUA2 for DAPI-stained cells (excitation 360-370 nm, emission 420-460 nm, dichromatic mirror 400); U-MNIB3 for FITC-labelled probes (excitation 470-495 nm, emission 500F, dichromatic mirror 500); U-MWIG3 for Cy3-labelled probes (excitation 530-550 nm, emission 575F, dichromatic mirror 570). We also carried out epifluorescence microscopy observations of WCL brine cells stained with the DNA-specific dye SYTO ${ }^{\mathrm{TM}} 9$ (ThermoFisher) following product specifications.

\section{Cultural approaches}

WCL brine samples were kept in the laboratory at room temperature and exposed to natural light. Cells were observed to slowly grow under these conditions. Subsamples of these brines were inoculated in a classical culture medium for halophiles (Rodriguez-Valera et al., 1980) slightly modified to match the $\mathrm{pH}$ and Mg concentrations of the WCLs (Tables S2-S3). Growth was monitored by optical microscopy using a Zeiss Axioplan microscope equipped with a Nikon Coolpix B500 color camera for image acquisition. 


\section{Results and Discussion}

280 During a recent expedition to the area of the Dallol protovolcanic salt-dome, we identified a thread of small hypersaline bubbling lakes lying north-northeast of the Round Mountain, which itself sits west to the geothermal Dallol dome at the base of the Ethiopian plateau escarpment (Fig.1A). The Round Mountain is a small mound sharing a similar aspect with the anhydritecapped halite salt canyons that characterize the western side of the Dallol dome (López-García et al., 2020), but is separated from it by the salt flat covering the bottom of the Danakil Depression. We named these brine ponds the Western Canyon Lakes (WCLs) and we collected samples from five of them (named WCL1 to WCL5; Fig.1B). The WCLs seem to have been rather stable systems over recent times; indeed, they were already mentioned in the 1960s (Holwerda and Hutchinson, 1968) and satellite images show a similar configuration for the WCL1-5 along the twenty-first century (Fig.S1).

\section{Physicochemistry of the Western Canyon Lakes}

During the 2019 expedition, we collected brine samples from the WCL1 to WCL5, as well as from two hypersaline life-hosting systems previously studied: a cave reservoir in the Dallol salt canyons (sample 9Gt) and Lake Assale (sample 9Ass-Isl), which was sampled in its center from the shore of one of its small islands (Table 1; Fig.1 and Fig.S2A-F). The WCLs displayed pH values between $4.8-5.1$, temperature $\sim 30^{\circ} \mathrm{C}$ and salinity between $33-41 \%(\mathrm{w} / \mathrm{v})$. In addition, we also measured physicochemical parameters and collected brines from the lifeless Dallol ponds and the nearby Black and Yellow lakes lying, respectively, southwestern and southeastern of the Dallol dome (Table S1; Fig.S2G-L) in order to enrich our comparative physicochemistry datasets. The sampled brines on top of the Dallol dome, located inside the crater-like structure 
hosting most hydrothermal manifestations, exhibited similar salinity $(35-45 \%), \mathrm{pH}(-0.79$ to $0.28)$ and temperature $\left(30-109^{\circ} \mathrm{C}\right)$ range as previously observed (Table S1) (Belilla et al., 2019). We analyzed the major and trace elements present in the WCLs and the other brines (Table S2) as well as the dominant anions and cations (Table S3). From the chemical point of view, the WCLs were overall more similar to the Lake Assale and the Dallol canyon cave reservoir brines, being dominated by $\mathrm{NaCl}$ salts albeit combined with other elements (Table S2) and exhibiting higher salinity (34-41\%) and lower pH ( 5) (Table 1). WCLs thus clustered with those samples in principal component analyses (PCA) (Fig.2 and Fig.S3). Nonetheless, WCL3 was relatively more enriched in Ca and $\mathrm{Mg}$ (Table S2), which placed it closer to the brines of the Black and Yellow lakes (Fig.S3). The Dallol brines clustered with samples collected from the dome in previous years, confirming their distinct chemistry, Na-dominated but extremely rich in Fe and other transition (e.g. Mn) and post-transition (notably Al) metals (Table S2; Fig.2 and Fig.S3) (Belilla et al., 2019; Kotopoulou et al., 2019). The WCLs were actively degassing, dispersing an odor suggestive of organic compounds. Organic chromatography analyses revealed the presence of $\mathrm{CO} \quad$, strongly suggesting that gas emissions were largely formed by this gas, but also a variety of organic compounds, notably hydrocarbons and N-rich compounds. Collectively, various linear and cyclic hydrocarbons, sometimes $\mathrm{N}$ - or S-rich, were present in the brines of the area (Table S4) (Belilla et al., 2019). These organic compounds likely derive from the quaternary organic-rich sediments interlayered within evaporitic deposits below the recent uppermost salt crust and remobilized by the up-flowing fluids (Darrah et al., 2013; Franzson et al., 2015; López-García et al., 2020).

Water activity $\left(\mathrm{a}_{\mathrm{w}}\right)$ and chaotropicity, strongly correlated with salinity and the nature of salts ( $\mathrm{Mg} \mathrm{Ca}$ and Fe chlorides being more chaotropic than $\mathrm{NaCl}$ ), are key determinants for active life 325 (Hallsworth et al., 2007; Hallsworth, 2019). Currently, life is known to develop at chaotropicity 
levels lower than $87.3 \mathrm{~kJ} / \mathrm{kg}$ and at water activity levels higher than 0.585 (Hallsworth et al., 2007; Stevenson et al., 2015; Stevenson et al., 2017). Measured chaotropicity in the WCLs varied from -15.6 to $-27.1 \mathrm{~kJ} / \mathrm{kg}$, and water activity, from 0.690 to 0.719 (Table 1). The WCLs exhibited, as for $\mathrm{pH}$ and salinity (Table 1), slightly more extreme values for those parameters than the cave reservoir and Lake Assale on average (a w, $0.718-0.731$; chaotropicity, -18.3 to $57.5 \mathrm{~kJ} / \mathrm{kg}$ ), albeit in principle still permissive for life. Accordingly, the WCLs detached from these life-hosting hypersaline systems in PCA analyses, becoming closer to the life-limiting physicochemical barriers associated to the Dallol and Yellow/Black Lake brines (Fig.2; Fig.S3). The water activity indeed reached lower values in the WCLs than those recently measured in acid brines considered close to life-limiting (0.714) (Benison et al., 2021).

\section{Low-diversity, archaea-dominated communities}

To ascertain whether microbial life thrived in the WCLs and characterize it, we retained the potential biomass in brines by filtering through $0.2 \mu \mathrm{m}$ pore-diameter filters and applied DNA purification protocols to carry out $16 \mathrm{~S} / 18 \mathrm{~S}$ rRNA gene amplicon metabarcoding analyses. We processed in the same way the newly obtained samples from Lake Assale (9Ass-Isl) and the Dallol canyon cave reservoir $(9 \mathrm{Gt})$. In all cases, we could easily obtain $16 \mathrm{~S}$ rRNA gene amplicons suggesting that prokaryotic communities were flourishing in these ecosystems. By contrast, 18S rRNA genes were difficult to amplify from the WCLs, despite the use of varying DNA amounts. Indeed, we only got amplicons from WCL2 and WCL4 (Table S5) after seminested PCR reactions, suggesting that eukaryotes were rare and/or absent from these lakes.

We applied high-throughput sequencing (MiSeq Illumina) to the amplified 16S/18S rRNA gene fragments and analyzed the resulting sequences using the well-established pipeline QIIME (Estaki et al., 2020). Minor modifications were used to ensure that molecular identifiers 
and primers were searched only at the $5^{\prime}$ ends of reads sequences during demultiplexing steps, and to orient all ASVs in the same direction before proceeding to downstream analyses. We applied DADA2 (Callahan et al., 2016) to generate ASVs that we used to define operational taxonomic units (OTUs) in our study (the terms ASV and OTU are therefore indistinctly used hereafter). For comparative purposes, we included in our analysis raw sequences obtained from brines in the Dallol area (cave reservoir, geothermally influenced salt plain, Lake Assale) sampled in previous years and treated in the same way (Table 1). On average, the number of ASVs/OTUs in the WCLs was smaller than in Lake Assale. OTU richness was similar or slightly smaller in the WCLs compared to the cave reservoir and geothermally influenced salt plain samples (Table S5; Fig.3). Archaeal OTUs were the most diverse in absolute numbers, in comparison with the two other life domains (Table S5). In addition, within prokaryotes, archaea were the most relatively abundant in all samples and, most particularly in the WCLs. Indeed, archaeal reads constituted $99.1 \pm 0.5 \%$ in the WCLs, while they were $88.8 \pm 8.4 \%$ in the cave reservoir, $84.2 \pm 2 \%$ in Lake Assale and $88.6 \pm 9 \%$ in the salt plain samples. Although highly dominant and relatively diverse, archaeal diversity was on average reduced in the most polyextreme systems (Fig.3A). These trends were well reflected in the observed richness for archaea and bacteria (Fig.3) and eukaryotes (Fig.4), as well as in other alpha-diversity parameters. Thus, the Simpson diversity index was maximal (lowest diversity) for archaea and, notably, bacteria (Fig.3). The same indices for eukaryotes (Fig.4) were not comparable, as they were calculated from independent sequence datasets that were, in addition, patchy (no eukaryotes detected in several samples) or amplified via semi-nested PCR approaches (WCL2, WCL4).

Therefore, our observations are consistent with the long-held ideas that diversity decreases as the environments become increasingly extreme close to life-limiting conditions and that 
archaeal adaptations excel in those conditions (Rothschild and Mancinelli, 2001; López-García, 2005).

\section{Phylogenetic diversity of life-boundary extremophiles}

The vast majority of the prokaryotic diversity in the WCLs encompassed members of two major archaeal groups, the Halobacteriota, which represented between 55 and $72 \%$ of archaeal sequences, and the Nanohaloarchaeota, which accounted for one third of prokaryotic sequences (35 $\pm 5.2 \%)$. Nanohaloarchaeota were therefore more highly and constantly represented in WCLs than in the other brines, where their proportion was only half of that reached in WCLs (14.3 $\pm 7.8 \%$ ) (Fig.3B). These groups were also overrepresented in deep-sea brines approaching the low water activity boundary for life (Yakimov et al., 2015; La Cono et al., 2019). Members of these two groups were not only abundant but also very diverse in terms of OTUs with approximately half of OTUs belonging to the Halobacteriota and a fourth to the Nanohaloarchaeota (Fig.5). We detected members of five haloarchaeal classes (as per the SILVA classification scheme) with members of the Haloferacaceae, Halomicrobiaceae, Halobacteriaceae and Halococcaceae being the most relatively abundant (Fig.S4). These families covered a wide diversity of genera (Table S6). A phylogenetic tree of sequences affiliating with the Halobacteriota including the WCL amplicon sequences, their closest BLAST hits and reference sequences in the haloarchaeal tree, showed that some WCL sequences might represent new genera within families or even some higher order clades within the Halobacteriota (Fig.S5). The latter is consistent with the fact that a proportion of $3-6 \%$ haloarchaeal sequences could not be assigned to known haloarchaeal taxa. Notably, a strongly supported and divergent group of sequences basal to all other haloarchaeal sequences might represent a novel class or order-level clade (WCL basal haloarchaeal clade; Fig.S5). Similarly, 
Nanohaloarchaeota, although largely affiliating to the only defined class Nanosalinaceae (Fig.S4), encompassed many sequences that did not branch very close to existing genera in 400 the phylogenetic tree (Fig.S6). Nonetheless, a fraction of nanohaloarchaeotal sequences branched off at the base of the Nanosalinaceae and might constitute a new class or order-level taxon (WCL basal nanohaloarchaeotal clade). Further phylogenetic analyses with longer sequences and additional (meta)genome-derived gene markers for these groups should confirm this basal position and shed light on their metabolic potential. uncultured and appear to be epibionts on other archaea, having reduced genomes (Castelle et al., 2018; Dombrowski et al., 2019). The first isolated nanohaloarchaeon was dependent on its haloarchaeal host, suggesting a parasitic interaction (Hamm et al., 2019). However, the symbiosis between nanohaloarchea and haloarchaea can become mutualistic depending on the environmental conditions, which might control the type of interaction along the parasitismmutualism continuum (López-García and Moreira, 2021). Thus, a mutualistic interaction based on the joint degradation of some polysaccharide compound occurs between Halomicrobium sp. LC1 Hm and its epibiont, Candidatus Nanohalobium constans LC1Nh (La Cono et al., 2020). A higher preference of the Nanohaloarchaeota for the most extreme saline conditions compared 415 to the more versatile Halobacteriota has been suggested (Ventosa et al., 2015; Menéndez-Serra et al., 2020). Whether the more extreme conditions enhance nanohaloarchaeotal parasitism or whether, under these conditions, some sort of enforced mutualism develops remains to be ascertained. The stable maintenance of these consortia over time should help testing these options. our samples virtually spans all along the archaeal tree as was previously observed in Lake 
Assale, the cave reservoir and the salt plain (Belilla et al., 2019). We identified lineages also typically associated with hypersaline environments, such as Methanonatronoarchaeia (Sorokin et al., 2017) and the Candidate Division MSBL1 (now reclassified as Hadarchaeota in some recent taxonomic schemes) (van der Wielen et al., 2005) (Borin et al., 2009), but also lineages not typically associated with hypersaline systems (Fig.5; Table S6). The latter included members of the euryarchaeal clades Thermoplasmatota and Archaeoglobi, the crenarchaeal (Thermoproteota) clades Nitrososphaeria (Thaumarchaeota) and Bathyarchaeia, as well as members of the Aenigmarchaeota, Altiarchaeales and Woesearchaeales. Members of the Hadarchaeota and Thermoproteota were only found in WCLs and Lake Assale (Fig.5; Table S6).

By contrast, the bacterial diversity identified in the WCLs was very limited, albeit it included members of some bacterial groups known for their adaptations to high salinity such as the Rhodothermia (Bacteroidota) that includes the halophilic Salinibacter among others (Oren and Rodriguez-Valera, 2001; Mongodin et al., 2005) (Fig.3; Table S7). The eukaryotic diversity was low and sporadic, being barely detectable in the WCLs (Fig.4; Table S8). When detected, microbial eukaryotes belonged mostly to the green algae, with well-known halophilic genera, such as Dunaliella (Stevenson et al., 2015; Gunde-Cimerman et al., 2018), and ciliates, some of which are also known to be extreme halophiles (Harding and Simpson, 2018).

\section{Cells and mineral biomorphs}

In order to identify cells potentially growing in the WCLs, we carried out optical and epifluorescence microscopy observations. These showed the presence of relatively abundant cells in the different WCLs that were usually small. Several cells appeared paired, suggesting recent cell division and active growth; other cells formed small aggregates (Fig.S7). FISH using 
archaea-specific probes suggested that many observed cells were archaea (Fig.S8), with ARC915 giving better signal than EURY498, known to poorly target haloarchaea compared to other classical Euryarchaeota (Burggraf et al., 1994). Finally, we also attempted to enrich in culture some of the WCL archaea. Preliminary data show the enrichment of various microbial morphotypes, including Haloarcula - and Haloquadratum -like organisms (Fig.S9).

To try to identify potential nanohaloarchaeal cells, usually of tiny sizes, we carried out scanning electron microscopy (SEM) observations. We observed typical small cocci, often in aggregates, with sizes ranging between few hundred nm up to $1 \mu \mathrm{m}$ (Fig.6). Some of these celllike aggregates were associated to various mineral precipitates (Fig.6A-B). In some case, 455 smaller (200-300 nm in diameter), epibiont-like cells were observed (arrows in Fig.6C and Fig.6E), which might correspond to nanohaloarchaea. They composed of organic material, i.e. they were clearly cells, as energy dispersive X-ray spectrometry (EDXS) spectra did not reveal chemical elements indicative of mineral phases present in the brines (Fig.6E). However, we also observed numerous aggregates of cell-looking rounded particles of comparable size to the 460 observed cells (Fig.6D) that turned out to be minerals. Most of these mineral biomorphs were Fe- and sometimes Ca- and Mg-rich silicates (Fig.6F-G). We also detected calcium sulfate precipitates, associated with some Fe and $\mathrm{Mg}$ (Fig.6H). These minerals might come from gypsum/anhydrite deposits outcropping on top of the Round Mountain (López-García et al., 2020). Halite, gypsum and also calcite have been found, among others, in sediments of Lake Afrera, further south long the Danakil Depression as a result from the interaction of hydrothermal fluids with evaporites and basalts (Bonatti et al., 2017). This process actively operates along the North Danakil Depression (Varet, 2018; López-García et al., 2020) and might be at the origin of compositionally diverse mineral precipitates. Mineral biomorphs of varied chemistry were indeed abundantly detected in the Dallol brines (Belilla et al., 2019; Kotopoulou et al., 2019). They can 
be erroneously mistaken with real cells (Gómez et al., 2019) and constitute severe confounding factors that limit the reliability of morphological (bio)signatures. Therefore, in the absence of multiple convergent evidence, morphological signatures in the fossil record and/or extraterrestrial material should be interpreted with the utmost caution (Garcia-Ruiz et al., 2003; Rouillard et al., 2018).

475

\section{Concluding remarks}

In this work, we analyzed microbial communities of newly explored hypersaline mildly acidic brines (WCLs) in the North Danakil Depression that display physicochemical parameter levels, notably water activity (as low as 0.690 ), approaching the conditions limiting for life that are encountered in the Dallol hyperacidic brines and highly chaotropic Black and Yellow Lakes nearby. These microbial communities in the WCLs are overwhelmingly dominated by archaea, which constitute around $99 \%$ of the total prokaryotic 16 S rRNA gene sequence reads. Bacteria were very minor components and so likely were eukaryotes, since $18 \mathrm{~S}$ rRNA genes were difficult or impossible to amplify even after semi-nested PCR reactions, suggesting rare and/or sporadic occurrences. Compared to other hypersaline but less extreme sites in the Danakil Depression, the WCLs displayed a decreased total and archaeal diversity, confirming diversity streamlining in the vicinity of life-limiting boundaries. Halobacteriota and Nanohaloarchaeota were by far the most dominant groups, although members of other archaeal phyla and some divergent groups were additionally identified. These communities are actively growing in the lakes as shown by direct optical and epifluorescence microscopy of WCL brines and FISH experiments. Finally, we visualize potential symbiotic consortia by SEM and also inorganic biomorphs, emphasizing the need to interpret with caution morphological signatures. Established cultural enrichments sustain hope for future isolation of halophilic strains and symbiotic consortia. The 
characterization of these and/or genome-resolved metagenomics should help to characterize the adaptations and metabolic potential of these polyextremophilic archaea.

\section{Acknowledgements}

We are grateful to Olivier Grunewald for co-organizing the field trips and providing drone images. We thank Jean-Marie Hullot (in memoriam), Françoise Brenckmann and the Fondation Iris

500 (Fondation de France) as well as the Mamont Frederik Paulsen Foundation for funding, respectively, the 2016 and 2019 field trips. We thank Luigi Cantamessa for the in situ logistics and discussions about local history, and Jacques Barthélémy for help during field trips. We thank Ana Gutiérrez-Preciado for help with sequence analysis, and Adrienne Kish and Charly Faveau for guidance on water activity measurements at the Muséum National d'Histoire Naturelle. We acknowledge Abdul Ahmed Aliyu and the Afar University and authorities for local assistance as well as the Ethiopian army and the Afar police for providing security. This research was funded by the European Research Council under the European Union's Seventh Framework Program (ERC Grant Agreement 322669 to PLG) and the CNRS programs TELLUS INTERRVIE and EC2CO.

\section{Author Contributions}

PLG and DM designed and supervised the research. PLG organized the scientific expeditions. PLG, DM, JB, KB and JMLG collected samples and took measurements in situ. JB carried out molecular biology experiments. JB, MI, DM and GR analyzed sequence data with help from PD.

$515 \mathrm{~KB}$ and JB carried out electron microscopy and EDXS observations. JMLG georeferenced all samples. AILA participated in the chemical analyses and produced enrichment cultures. EG 
assisted MI with FISH experiments. PLG and DM wrote the manuscript with input from JB; it was then critically read and approved by all authors.

\section{References}

Asnicar, F., Weingart, G., Tickle, T.L., Huttenhower, C., and Segata, N. (2015) Compact graphical representation of phylogenetic data and metadata with GraPhIAn. PeerJ 3:e1029.

Belilla, J., Moreira, D., Jardillier, L., Reboul, G., Benzerara, K., López-García, J.M. et al. (2019) Hyperdiverse archaea near life limits at the polyextreme geothermal Dallol area. Nature Ecol Evol 3: 1552-1561.

Benison, K.C., O'Neill, W.K., Blain, D., and Hallsworth, J.E. (2021) Water activities of acid brine lakes approach the limit for life. Astrobiology.

Bonatti, E., Emiliani, C., Ostlung, G., and Rydell, H. (1971) Final desiccation of Afar Rift, Ethiopia. Science 172: 468-469.

Bonatti, E., Gasperini, E., Vigliotti, L., Lupi, L., Vaselli, O., Polonia, A., and Gasperini, L. (2017) Lake Afrera, a structural depression in the Northern Afar Rift (Red Sea).

Heliyon 3: e00301.

Borin, S., Brusetti, L., Mapelli, F., D'Auria, G., Brusa, T., Marzorati, M. et al. (2009) Sulfur cycling and methanogenesis primarily drive microbial colonization of the highly sulfidic Urania deep hypersaline basin. Proc Nat/Acad SciUSA 106:9151-9156.

535 Burggraf, S., Mayer, T., Amann, R., Schadhauser, S., Woese, C.R., and Stetter, K.O. (1994) Identifying members of the domain Archaea with rRNA-targeted oligonucleotide probes. Appl Environ Microbiol 60: 3112-3119.

Callahan, B.J., McMurdie, P.J., Rosen, M.J., Han, A.W., Johnson, A.J.A., and Holmes, S.P. (2016) DADA2: High-resolution sample inference from Illumina amplicon data. Methods 13: 581-583.

Capella-Gutierrez, S., Silla-Martinez, J.M., and Gabaldon, T. (2009) trimAl: a tool for automated alignment trimming in large-scale phylogenetic analyses. Bioinformatics 25: 1972-1973.

Castelle, C.J., Brown, C.T., Anantharaman, K., Probst, A.J., Huang, R.H., and Banfield, J.F. (2018) Biosynthetic capacity, metabolic variety and unusual biology in the CPR and DPANN radiations. Nat Rev Microbiol 16:629-645.

Cavalazzi, B., Barbieri, R., Gomez, F., Capaccioni, B., Olsson-Francis, K., Pondrelli, M. et al. (2019) The Dallol geothermal area, Northern Afar (Ethiopia)-An exceptional planetary field analog on Earth. Astrobiology 19: 553-578.

Cray, J.A., Russell, J.T., Timson, D.J., Singhal, R.S., and Hallsworth, J.E. (2013) A universal measure of chaotropicity and kosmotropicity. Environ Microbio/ 15: 287-296. 
Darrah, T.H., Tedesco, D., Tassi, F., Vaselli, O., Cuoco, E., and Poreda, R.J. (2013) Gas chemistry of the Dallol region of the Danakil Depression in the Afar region of the northernmost East African Rift. Chem Geol 339: 16-29.

Dombrowski, N., Lee, J.H., Williams, T.A., Offre, P., and Spang, A. (2019) Genomic diversity, lifestyles and evolutionary origins of DPANN archaea. FEMS Microbiol Lett 366: fnz008.

Escudero, L.V., Bijman, J., Chong, G., Pueyo, J.J., and Demergasso, C. (2013) Geochemistry and microbiology in an acidic, high altitude $(4,000 \mathrm{~m})$ salt flat, High Andes, Northern Chile. In Integration of Scientific and Industrial Knowledge on Biohydrometallurgy . Guiliani, N., Demergasso, C., Quatrini, R., Remonsellez, F., DavisBelmar, C., Levican, G. et al. (eds), pp. 28-+.

Estaki, M., Jiang, L., Bokulich, N.A., McDonald, D., González, A., Kosciolek, T. et al. (2020) QIIME 2 enables comprehensive end-to-end analysis of diverse microbiome data and comparative studies with publicly available data. Curr Protoc Bioinformatics 70: e100.

Franzson, H., Helgadóttir, H.M., and Óskarsson, F. (2015) Surface exploration and first conceptual model of the Dallol geothermal area, Northern Afar, Ethiopia. In Proceedings World Geothermal Congress . Melbourne, Australia, p. 11.

Garcia-Ruiz, J.M., Hyde, S.T., Carnerup, A.M., Christy, A.G., Van Kranendonk, M.J., and Welham, N.J. (2003) Self-assembled silica-carbonate structures and detection of ancient microfossils. Science 302:1194-1197.

570 Gómez, F., Cavalazzi, B., Rodríguez, N., Amils, R., Ori, G.G., Olsson-Francis, K. et al. (2019) Ultra-small microorganisms in the polyextreme conditions of the Dallol volcano, Northern Afar, Ethiopia. Sci Rep 9: 7907.

Gunde-Cimerman, N., Plemenitaš, A., and Oren, A. (2018) Strategies of adaptation of microorganisms of the three domains of life to high salt concentrations. FEMS Microbiol Rev 42: 353-375.

Hallsworth, J.E. (2019) Microbial unknowns at the saline limits for life. $\quad$ Nat Ecol Evol 3: 15031504.

Hallsworth, J.E., Yakimov, M.M., Golyshin, P.N., Gillion, J.L., D'Auria, G., de Lima Alves, F. et al. (2007) Limits of life in MgCl2-containing environments: chaotropicity defines the window. Environ Microbiol 9: 801-813.

Hamm, J.N., Erdmann, S., Eloe-Fadrosh, E.A., Angeloni, A., Zhong, L., Brownlee, C. et al. (2019) Unexpected host dependency of Antarctic Nanohaloarchaeota.

Proc Natl Acad SciU $S A$ 116: 14661-14670.

Harding, T., and Simpson, A.G.B. (2018) Recent advances in halophilic protozoa research. 
Harrison, J.P., Gheeraert, N., Tsigelnitskiy, D., and Cockell, C.S. (2013) The limits for life under multiple extremes. Trends Microbiol 21: 204-212.

Holwerda, J.G., and Hutchinson, R.W. (1968) Potash-bearing evaporites in the Danakil area, Ethiopia. Economic Geology 63: 124-150.

Johnson, S.S., Chevrette, M.G., EhImann, B.L., and Benison, K.C. (2015) Insights from the metagenome of an acid salt lake: the role of biology in an extreme depositional environment. PLoS One 10: e0122869.

Kassambara, A., and Mundt, F. (2017) factoextra: Extract and visualize the results of multivariate data analyses. In: https://CRAN.R-project.org/package=factoextra .

595 Katoh, K., and Standley, D.M. (2013) MAFFT multiple sequence alignment software version 7: improvements in performance and usability. Mol Biol Evol 30: 772-780.

Kotopoulou, E., Delgado Huertas, A., Garcia-Ruiz, J.M., Dominguez-Vera, J.M., Lopez-Garcia, J.M., Guerra-Tschuschke, I., and Rull, F. (2019) A polyextreme hydrothermal system controlled by iron: The case of Dallol at the Afar Triangle. ACS Earth Space Chem 3:90-99.

La Cono, V., Bortoluzzi, G., Messina, E., La Spada, G., Smedile, F., Giuliano, L. et al. (2019) The discovery of Lake Hephaestus, the youngest athalassohaline deep-sea formation on Earth. Sci Rep 9: 1679.

La Cono, V., Messina, E., Rohde, M., Arcadi, E., Ciordia, S., Crisafi, F. et al. (2020) Symbiosis between nanohaloarchaeon and haloarchaeon is based on utilization of different polysaccharides. Proc Nat/Acad SciUSA 117:20223-20234.

Lê, S., Josse, J., and Husson, F. (2008) FactoMineR: An R package for multivariate analysis. Journal of Statistical Software 25:1-18.

Lee, C.J.D., McMullan, P.E., O'Kane, C.J., Stevenson, A., Santos, I.C., Roy, C. et al. (2018) $\mathrm{NaCl}$-saturated brines are thermodynamically moderate, rather than extreme, microbial habitats. FEMS Microbiol Rev 42: 672-693.

López-García, J.M., Moreira, D., Benzerara, K., Grunewald, O., and López-García, P. (2020) Origin and evolution of the halo-volcanic complex of Dallol: proto-volcanism in Northern Afar (Ethiopia). Frontiers in Earth Science 7:351.

López-García, P. (2005) Extremophiles. In ～Lectures in Astrobiology . Gargaud, M., Barbier, B., 615 Martin, H., and Reisse, J. (eds). Heidelberg: Springer-Verlag, pp. 657-679.

López-García, P., and Moreira, D. (2021) Physical connections: prokaryotes parasitizing their kin. Environ Microbiol Rep 13:54-61.

Martin, M. (2011) Cutadapt removes adapter sequences from high-throughput sequencing reads. EMBnetJournal 17:10-12. 
Menéndez-Serra, M., Ontiveros, V.J., Triadó-Margarit, X., Alonso, D., and Casamayor, E.O.

(2020) Dynamics and ecological distributions of the Archaea microbiome from inland saline lakes (Monegros Desert, Spain). FEMS Microbiol Ecol 96.

Merino, N., Aronson, H.S., Bojanova, D.P., Feyhl-Buska, J., Wong, M.L., Zhang, S., and Giovannelli, D. (2019) Living at the extremes: Extremophiles and the limits of life in a planetary context. Front Microbiol 10: art 780.

Mesbah, N.M., and Wiegel, J. (2012) Life under multiple extreme conditions: diversity and physiology of the halophilic alkalithermophiles. App/ Environ Microbiol 78: 4074-4082.

Mongodin, E.F., Nelson, K.E., Daugherty, S., Deboy, R.T., Wister, J., Khouri, H. et al. (2005) The genome of Salinibacter ruber : convergence and gene exchange among hyperhalophilic bacteria and archaea. Proc Natl Acad SciUSA $\quad$ 102: 18147-18152.

Mormile, M.R., Hong, B.-Y., and Benison, K.C. (2009) Molecular analysis of the microbial communities of Mars analog lakes in Western Australia. Astrobiology 9: 919-930.

Nguyen, L.T., Schmidt, H.A., von Haeseler, A., and Minh, B.Q. (2015) IQ-TREE: a fast and effective stochastic algorithm for estimating maximum-likelihood phylogenies. Mol Biol Evol 32: 268-274.

Oksanen, J., Blanchet, G., Kindt, R., Legendre, P., O'Hara, R.B., Simpson, G.L. et al. (2011) Vegan: Community Ecology Package. $\mathrm{R}$ package version 1.17-9. In. http://CRAN.Rproject.org/package=vegan (ed): http://CRAN.R-project.org/package=vegan

Oren, A., and Rodriguez-Valera, F. (2001) The contribution of halophilic Bacteria to the red coloration of saltern crystallizer ponds. FEMS Microbiol Ecol 36: 123-130.

Pedgley, D.E. (1967) Air temperature at Dallol, Ethiopia. Meteorological Magazine 96: 265-271.

Quast, C., Pruesse, E., Yilmaz, P., Gerken, J., Schweer, T., Yarza, P. et al. (2013) The SILVA ribosomal RNA gene database project: improved data processing and web-based tools. Nucleic Acids Res 41: D590-596.

645 R Development Core Team (2017) R: A language and environment for statistical computing. In. http://www.r-project.org (ed). Vienna, Austria: R Foundation for Statistical Computing.

Rodriguez-Valera, F., Ruiz-Berraquero, F., and Ramos-Cormenzana, A. (1980) Behaviour of mixed populations of halophilic bacteria in continuous cultures. Can J Microbiol 26: 12591263.

650 Rothschild, L.J., and Mancinelli, R.L. (2001) Life in extreme environments.

Nature 409: 10921101.

Rouillard, J., García-Ruiz, J.-M., Gong, J., and van Zuilen, M.A. (2018) A morphogram for silicawitherite biomorphs and its application to microfossil identification in the early earth rock record. Geobiology 16: 279-296. 

Opin Microbiol 25: 88-96.

Sorokin, D.Y., Makarova, K.S., Abbas, B., Ferrer, M., Golyshin, P.N., Galinski, E.A. et al. (2017) Discovery of extremely halophilic, methyl-reducing euryarchaea provides insights into the evolutionary origin of methanogenesis. Nat Microbiol 2: 17081.

Stevenson, A., Hamill, P.G., O'Kane, C.J., Kminek, G., Rummel, J.D., Voytek, M.A. et al. (2017) Aspergillus penicillioides differentiation and cell division at 0.585 water activity. Microbiol 19: 687-697.

Stevenson, A., Cray, J.A., Williams, J.P., Santos, R., Sahay, R., Neuenkirchen, N. et al. (2015) Is there a common water-activity limit for the three domains of life? ISMEJ 9: 1333-1351. van der Wielen, P.W., Bolhuis, H., Borin, S., Daffonchio, D., Corselli, C., Giuliano, L. et al. (2005) The enigma of prokaryotic life in deep hypersaline anoxic basins. Science 307: 121-123. Varet, J. (2018) Recent and active units of the Danakil Sea (Dagad Salt Plain) and Afdera Lake. In Geology of Afar (East Africa) Regional Geology Reviews ～. Oberhänsli, R., de Wit, M.J., and Roure, F.M. (eds). Cham: Springer, pp. 205-226.

Ventosa, A., de la Haba, R.R., Sánchez-Porro, C., and Papke, R.T. (2015) Microbial diversity of hypersaline environments: a metagenomic approach. Curr Opin Microbiol 25: 80-87.

Warren, J.K. (2015) Danakhil potash, Ethiopia: Beds of kainite/carnallite, Part 2 of 4. In.

Yakimov, M.M., La Cono, V., Spada, G.L., Bortoluzzi, G., Messina, E., Smedile, F. et al. (2015) Microbial community of the deep-sea brine Lake Kryos seawater-brine interface is active below the chaotropicity limit of life as revealed by recovery of mRNA.

Environ Microbiol 17: 364-382.

Zaikova, E., Benison, K.C., Mormile, M.R., and Johnson, S.S. (2018) Microbial communities and their predicted metabolic functions in a desiccating acid salt lake. Extremophiles 22: 367379. 


\section{FIGURE LEGENDS}

Fig. 1. Localization of the sampling sites in the Danakil Depression (Ethiopia). A, Satellite view of the Northern Danakil Depression and the dome of Dallol showing the three zones visited in 2019 from where microbial communities were studied (B-D).

B, Detail of the Western Canyon Lakes adjacent to the Round Mountain (WCL1 to 5). C, The cave reservoir (with the sampling pole for scale) from which sample $9 \mathrm{Gt}$ was collected. D, Aerial view of the small islands in the middle of Lake Assale / Karum and the spot from which plankton was sampled close to the island shore. The dots indicate specific sampling points and the corresponding sample names. Satellite pictures are available from CNES (Centre National d'Etudes Spatiales) and distributed by Google Earth. North always faces the top of satellite pictures.

Fig. 2. Principal component analyses (PCA) of brine samples as a function of physicochemical parameters. A, PCA of brine samples (46 in total) according to the major dominant elements. Different types of correlating metals were grouped. A detailed PCA with sample names and unmerged variables is given in Fig. S3. B, PCA of brine simples (27 in total) as a function of the main environmental drivers and life-limiting parameters. P.t., post-transition. Colored zones in PCA analyses highlight groups of related samples.

Fig. 3. Diversity of archaea and bacteria in the Western Canyon Lakes and other hypersaline systems in the Danakil Depression, Ethiopia. A, alpha-diversity estimators of archaea and bacteria. Archaeal and bacterial alpha-diversity values are directly comparable (derive from the same $16 \mathrm{~S}$ rRNA gene amplicon sequence libraries). D, Simpson index. Note that the Simpson index varies between 0 (maximal diversity) and 1 (minimal diversity). 
relative proportion of archaeal and bacterial 16S rRNA gene amplicon sequences in prokaryotic libraries. WCL1-5, Western Canyon Lakes 1 to 5. Gt-samples correspond to the cave brine in the Dallol salt canyons. Ass-samples indicate samples from Lake Assale or Karum. PS-PS3, samples collected from the salt plain near the Dallol dome. Samples labelled with an asterisk were analyzed in a previous study (Belilla et al., 2019) and are included for comparison.

Fig. 4. Eukaryotic diversity identified in the Western Canyon Lakes and other hypersaline systems in the Danakil Depression, Ethiopia. A, alpha-diversity estimators. B, histogram showing the phylogenetic affiliation and abundance of 18S rRNA gene amplicon reads of eukaryotes obtained with universal eukaryotic primers. Only a few samples yielded amplicons. The phylogenetic affiliation of dominant eukaryotic groups is color-coded. Ass, Lake Assale or Karum; Gt, cave in the Dallol salt canyons; Ps, salt plain at the base of the Dallol dome; WCL, Western Canyon Lakes. D, Simpson index.

Fig. 5. Phylogenetic tree of archaeal 16S rRNA gene sequences showing the phylogenetic 720 placement of archaea identified in the Western Canyon Lakes and other life-sustaining hypersaline systems in the Dallol area. The newly generated archaeal sequences are indicated by blue branches. Near-full Sanger archaeal sequences previously obtained from some samples (Belilla et al., 2019) included here for comparison are labelled with red dots. Concentric circles around the tree indicate the presence/absence of the corresponding archaeal OTUs in the different sampling sites.

Fig. 6. Scanning electron micrographs and EDXS chemical maps of cells and abiotic biomorphs identified in the brines of the Western Canyon Lakes.

A-B, Cells (arrowheads) on mineral 
precipitates common in WCL samples. C, Close picture of a likely archaeal cell bearing an epibiont (arrow) potentially belonging to Nanohaloarchaeota. D, Close picture of round-shaped silicate biomorphs frequent in WCL. E-I, SEM pictures showing cells and/or mineral precipitates and associated chemical maps on the right. The brighter the color, the higher the concentration of the concerned element. E, A group of cells with potential epibionts (arrows) and a cube of halite (star) on top of amorphous silica. F, Cells (arrowheads) and biomorphs similar to (D) enriched in $\mathrm{Si}$ and Fe. G, Small round-shaped Si-Fe-rich biomorphs.

H, Gypsum-like precipitates with some Fe and Mg. The corresponding EDXS hypermap spectra are shown in (for $E)$, J (F), K (G) and L (H). 
Table 1. Samples collected to study their microbial communities from the Western Canyon Lakes in the vicinity of the Round Mountain and other Dallol area sites. RI, refractometer-inferred salinity, refers to the percentage $(\mathrm{w} / \mathrm{v})$ of salt measured in situ with a refractometer. Salinity was also measured by weighting the total solids after water evaporation (dry weight measured in

745 triplicates). Additional, lifeless brine samples were collected from the Dallol dome hyperacid ponds as well as the Black and Yellow Lakes in 2019 (Table S1). DO, dissolved oxygen; ORP, oxidation-reduction potential; TS, total solids; SD, standard deviation; n.d., not determined.

\section{Coordinates}

\section{S ampl}

e name

name

\section{Physicochemical parameters}

\begin{tabular}{|c|c|c|c|c|c|c|c|c|c|}
\hline $\begin{array}{c}\text { Collection } \\
\text { date }\end{array}$ & $\begin{array}{c}\text { Tem } \\
\text { p. } \\
\left({ }^{\circ} \mathrm{C}\right)\end{array}$ & $\mathrm{pH}$ & $\begin{array}{c}D \\
0 \\
(\% \\
)\end{array}$ & $\begin{array}{l}\text { ORP } \\
(\mathrm{mV})\end{array}$ & $\begin{array}{c}\text { RI } \\
\text { salinity } \\
(\%)\end{array}$ & $\begin{array}{c}\text { Salinity - } \\
\text { TS (g/) } \pm \\
\text { SD }\end{array}$ & $\begin{array}{c}\text { Water } \\
\text { activit } \\
y\end{array}$ & $\begin{array}{c}\text { Chaotro } \\
\text {-picity } \\
\text { (kJ/kg) }\end{array}$ & R eference \\
\hline
\end{tabular}

R ound Mountain / Western canyon lakes

\begin{tabular}{|c|c|c|c|c|c|c|c|c|c|c|c|c|}
\hline WCL1 & $\begin{array}{c}40.26805 \\
3\end{array}$ & $\begin{array}{c}14.2415 i \\
1\end{array}$ & & 29.33 & $\begin{array}{c}4.8 \\
5\end{array}$ & 32 & $\begin{array}{c}165.4 \\
3\end{array}$ & 30 & $\begin{array}{c}404.1 \pm \\
20.1\end{array}$ & 0.719 & -2.7 .1 & this studiy \\
\hline WCL2 & $\begin{array}{c}40.26797 \\
5\end{array}$ & $\begin{array}{c}14.24191 \\
4\end{array}$ & & 29.2 & $\begin{array}{c}5.0 \\
7\end{array}$ & 30 & 164.6 & 35 & $\begin{array}{c}338.6 \pm \\
35.4\end{array}$ & 0.716 & -19.1 & this studiy \\
\hline WCL3 & $\begin{array}{c}40.26785 \\
3\end{array}$ & $\begin{array}{c}14.24213 \\
9\end{array}$ & $\begin{array}{c}18.01 .201 \\
9\end{array}$ & 30.50 & $\begin{array}{c}4.9 \\
3\end{array}$ & 30 & 130 & n.d & $\begin{array}{c}412.5 \pm \\
18.2\end{array}$ & 0.690 & -17.3 & this study \\
\hline WCL5 & $\begin{array}{c}40.26716 \\
4\end{array}$ & $\begin{array}{c}14.242 ! i \\
1\end{array}$ & & 29.30 & $\begin{array}{c}5.1 \\
0\end{array}$ & 26 & 119.8 & 32 & $\begin{array}{c}337.8 \pm \\
11.7\end{array}$ & 0.725 & -15.6 & this studiy \\
\hline
\end{tabular}

Lake Assale / Karum

\begin{tabular}{|c|c|c|c|c|c|c|c|c|c|c|c|c|}
\hline Ass & $\begin{array}{c}40.34858 \\
3\end{array}$ & $\begin{array}{c}14.08956 \\
7\end{array}$ & $\begin{array}{c}23.01 .201 \\
6\end{array}$ & 26.20 & $\begin{array}{c}6.6 \\
8\end{array}$ & 53 & 97.70 & 20 & $\begin{array}{c}360.7 \pm \\
11.5\end{array}$ & 0.718 & n.d. & $\begin{array}{l}\text { Belilla et al., } \\
2019\end{array}$ \\
\hline $\begin{array}{c}\text { 9Ass- } \\
|s|\end{array}$ & $\begin{array}{c}40.38110 \\
3\end{array}$ & $\begin{array}{c}14.05364 \\
7\end{array}$ & $\begin{array}{c}23.01 .201 \\
9\end{array}$ & 30.60 & $\begin{array}{c}6.7 \\
0\end{array}$ & 46 & $\begin{array}{c}184.3 \\
0\end{array}$ & 29 & $302.3 \pm 4.7$ & 0.771 & n.d. & this study \\
\hline
\end{tabular}

Dallol dome salt canyon cave (water reservoir)

\begin{tabular}{|c|c|c|c|c|c|c|c|c|c|c|c|c|}
\hline $9 \mathrm{Gt}$ & 40.28995 & 14.22970 & $\begin{array}{c}16.01 .201 \\
9\end{array}$ & 25.50 & $\begin{array}{c}5.9 \\
4\end{array}$ & 46 & $\begin{array}{c}240.3 \\
0\end{array}$ & 30 & $325.3 \pm 5.4$ & 0.725 & n.d. & this study \\
\hline Gt & 2 & 4 & $\begin{array}{c}18.01 .201 \\
6\end{array}$ & n.d & n.d & $\begin{array}{l}\text { n. } \\
\text { d }\end{array}$ & n.d & 30 & n.d & 0.728 & n.d. & $\begin{array}{l}\text { Belilla et al., } \\
2019\end{array}$ \\
\hline
\end{tabular}


$323.8 \pm$

19.4

0.729

$-18.3$

Belilla et al., 2019

S alt plain at the Dallol dome base (salt crusts and small brine pockets)

\begin{tabular}{|c|c|c|c|c|c|c|c|c|c|c|c|c|}
\hline PS & $\begin{array}{c}40.28890 \\
0\end{array}$ & $\begin{array}{c}14.22501 \\
9\end{array}$ & $\begin{array}{c}19.01 .201 \\
6\end{array}$ & n.d & n.d & $\begin{array}{l}\mathrm{n} . \\
\mathrm{d}\end{array}$ & n.d & n.d & n.d & n.d. & n.d. & $\begin{array}{l}\text { Belilla et al., } \\
2019\end{array}$ \\
\hline PS3 & $\begin{array}{c}40.29793 \\
5\end{array}$ & $\begin{array}{c}14.22912 \\
0\end{array}$ & $\begin{array}{c}19.01 .201 \\
6\end{array}$ & 29.3 & $\begin{array}{r}4.2 \\
1\end{array}$ & $\begin{array}{l}\text { n. } \\
\text { d }\end{array}$ & n.d & 20.0 & $\begin{array}{c}352.6 \pm \\
10.8\end{array}$ & n.d. & n.d. & $\begin{array}{l}\text { Belilla et al., } \\
2019\end{array}$ \\
\hline
\end{tabular}



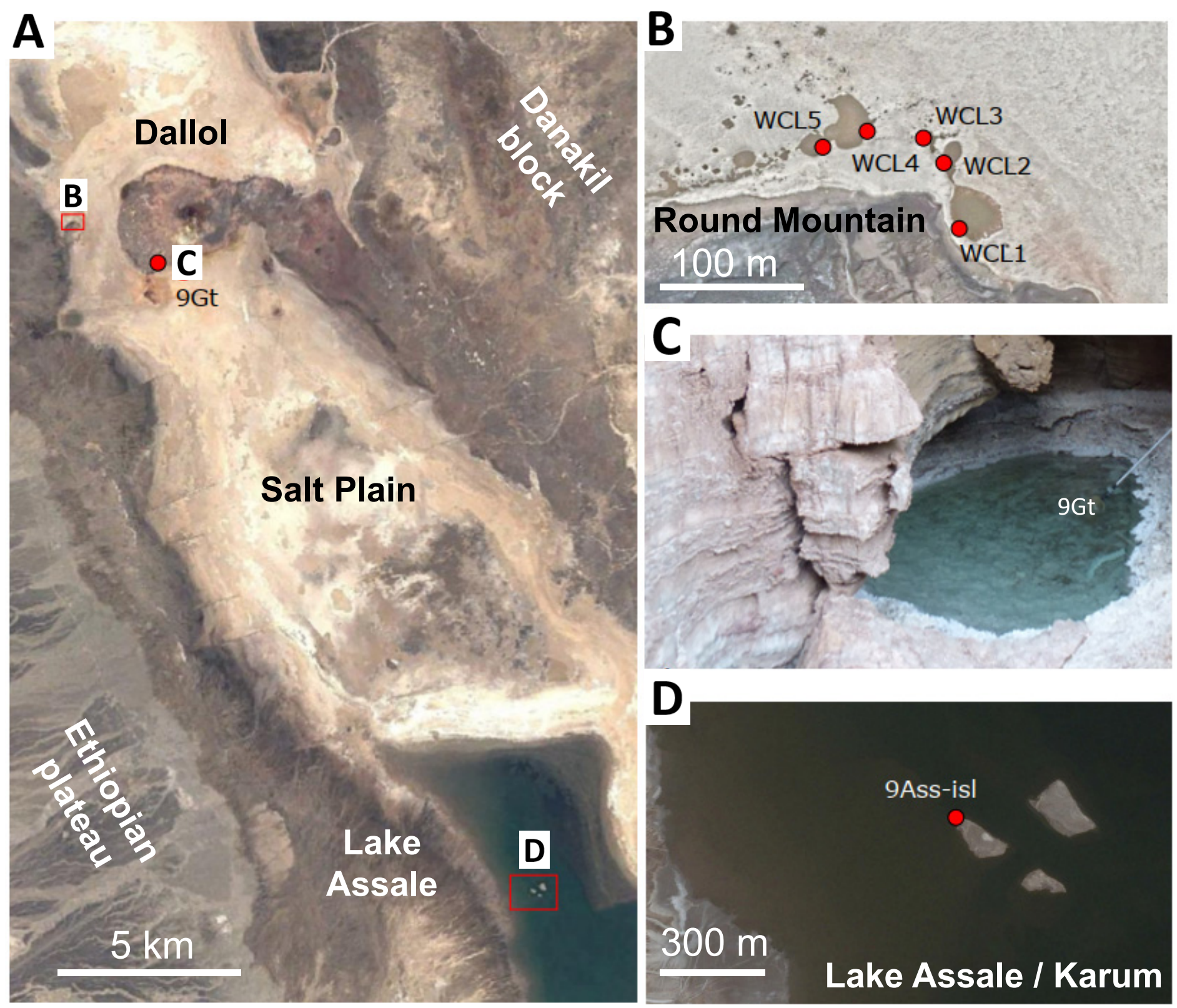

Fig.1. Belilla, Iniesto et al. 
${ }^{\mathrm{Pa}} \mathrm{A}^{35 \text { of } 39}$

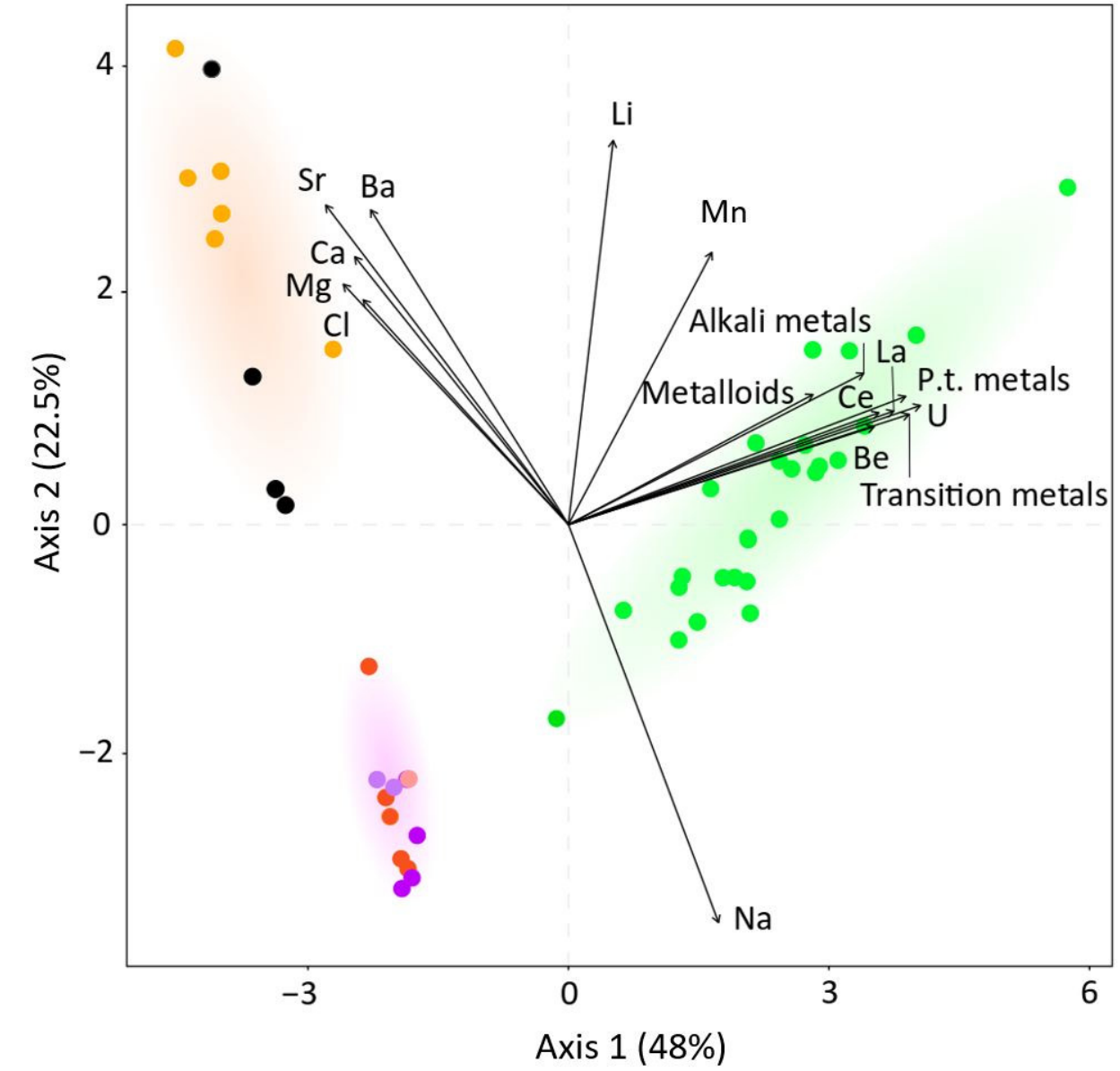
- Western Canyon Lakes
- Assale Lake
Salt Plain (PS3)

B

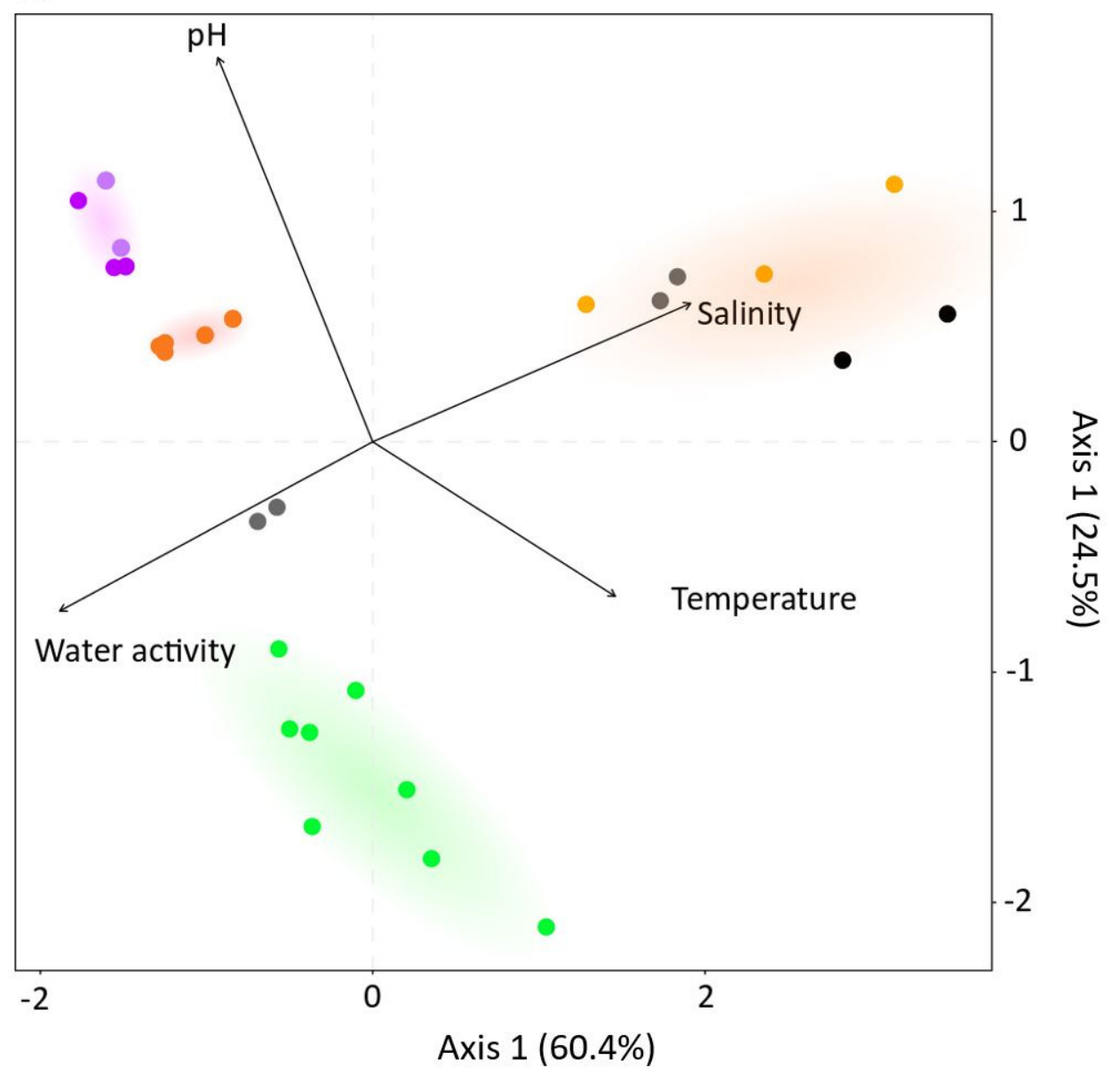

- Dallol ponds

- Black Lake

- Yellow Lake
- Black Lake area

Fig.2. Belilla, Iniesto et al. 
Archaea
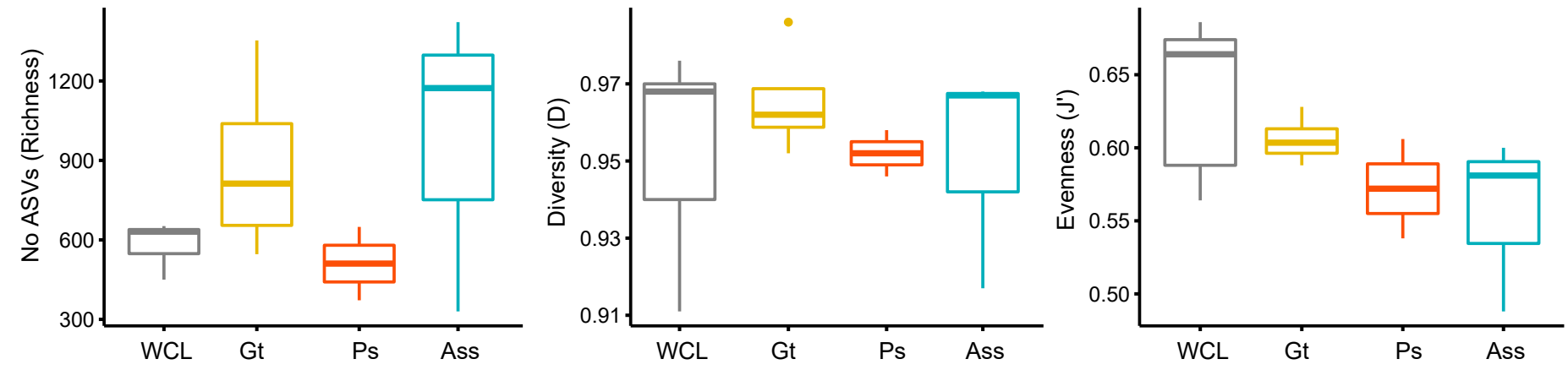

\section{Bacteria}
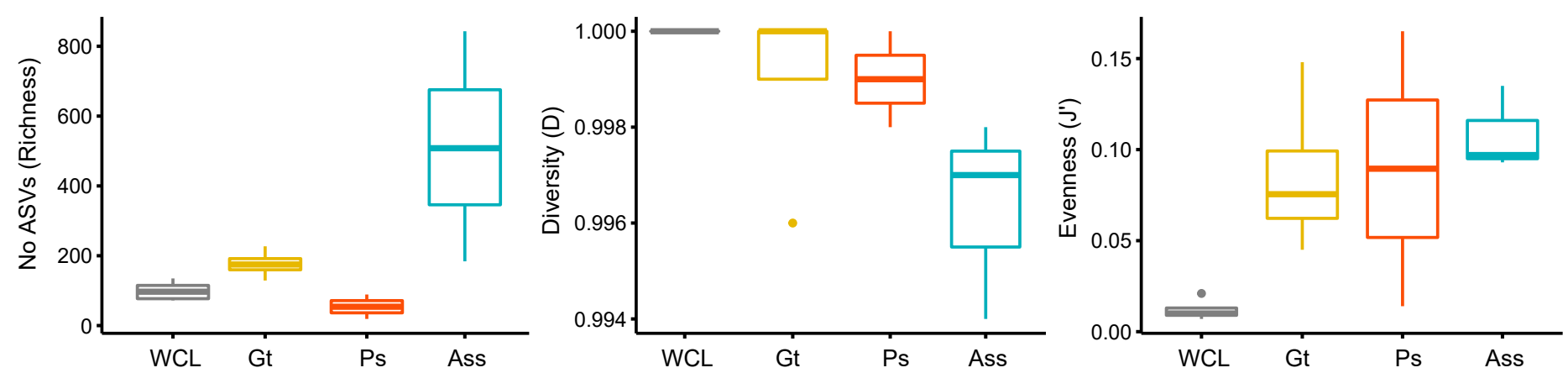

B

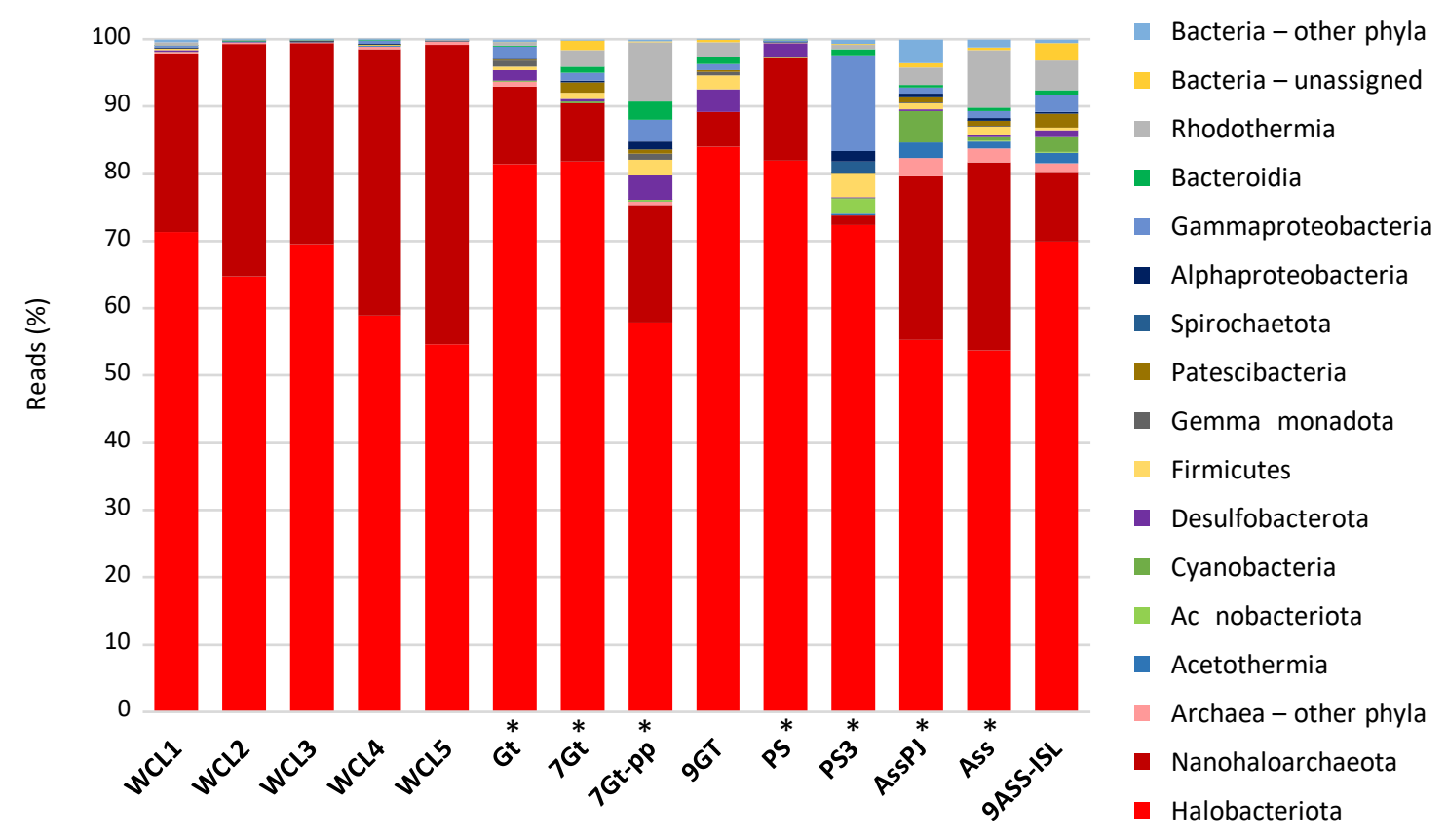

Fig. 3. Belilla, Iniesto et al. 
A
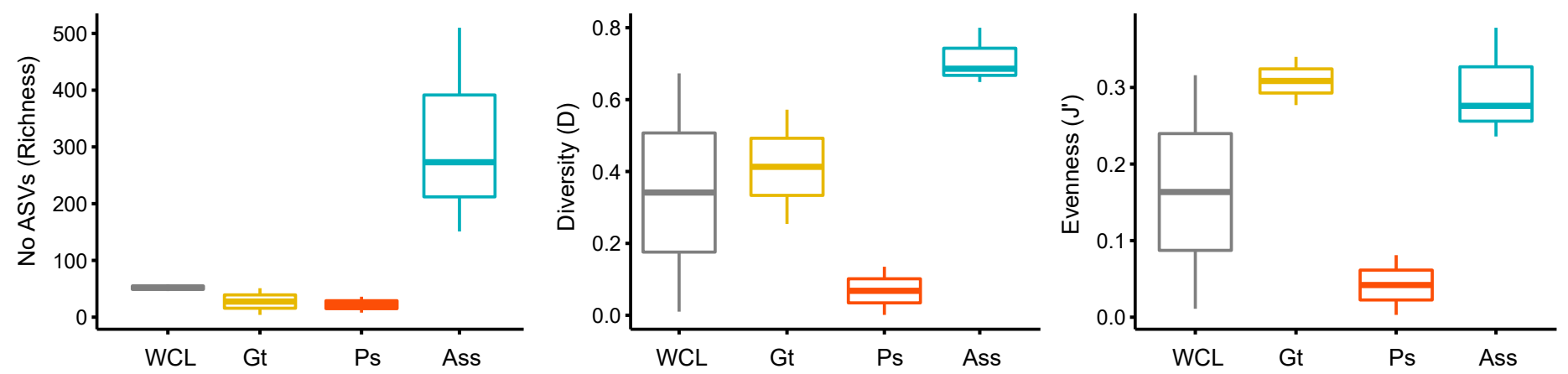

B

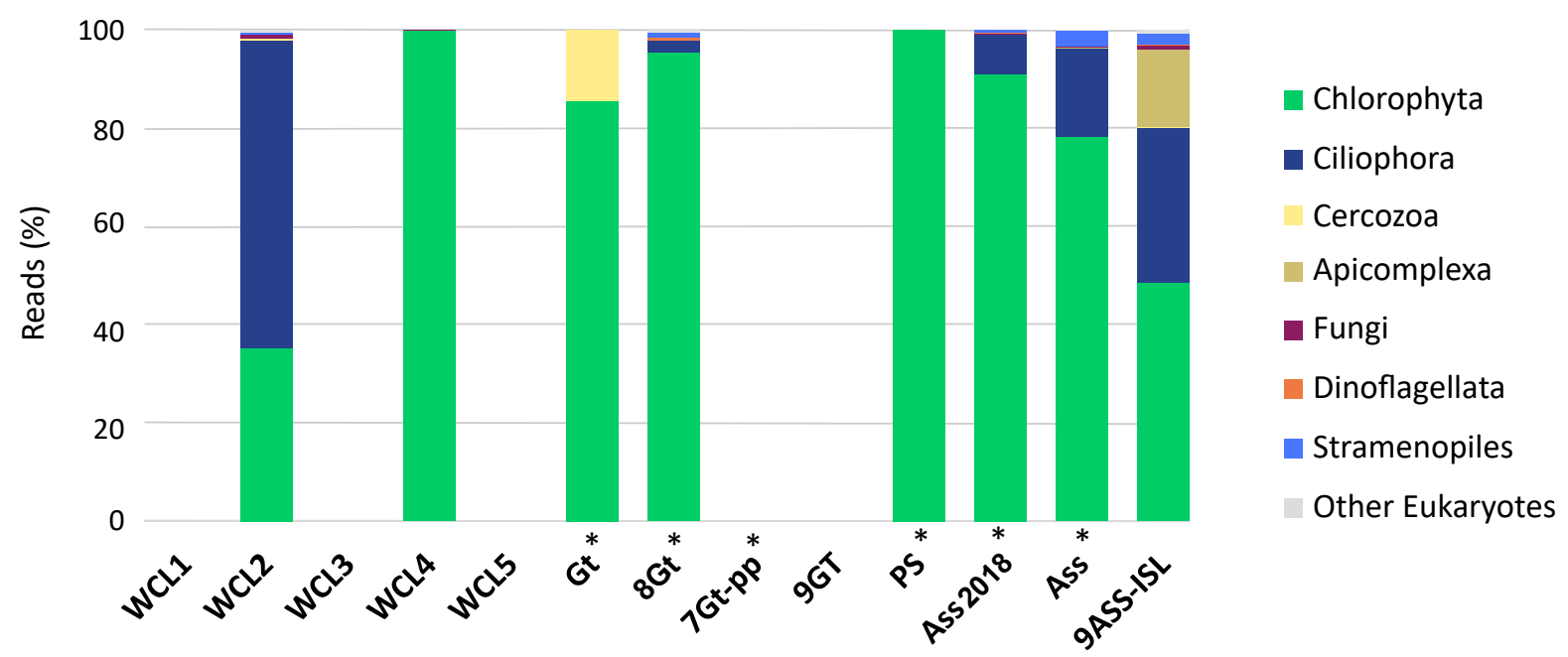

Fig. 4. Belilla, Iniesto et al. 


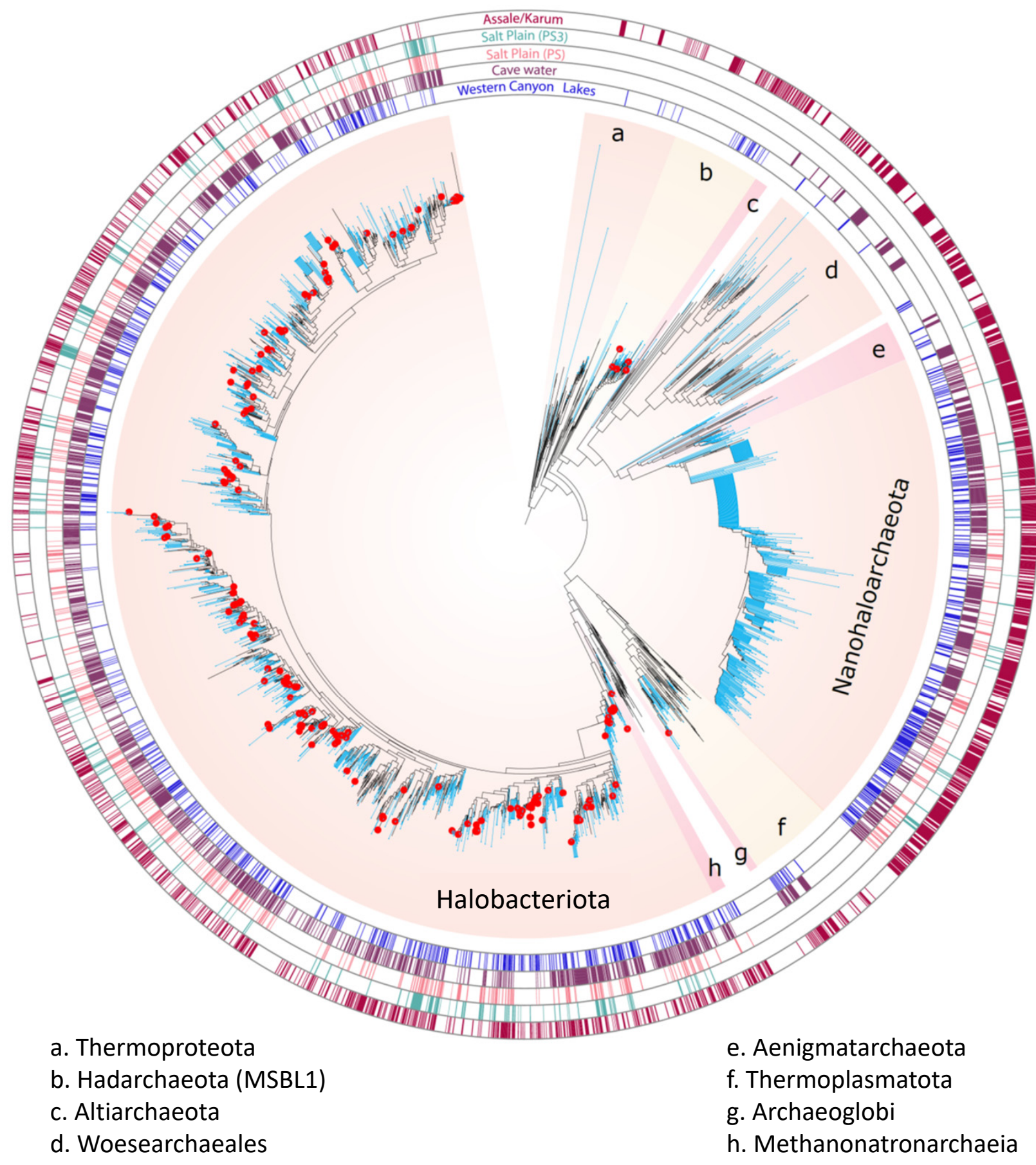

Fig.5. Belilla, Iniesto et al. 

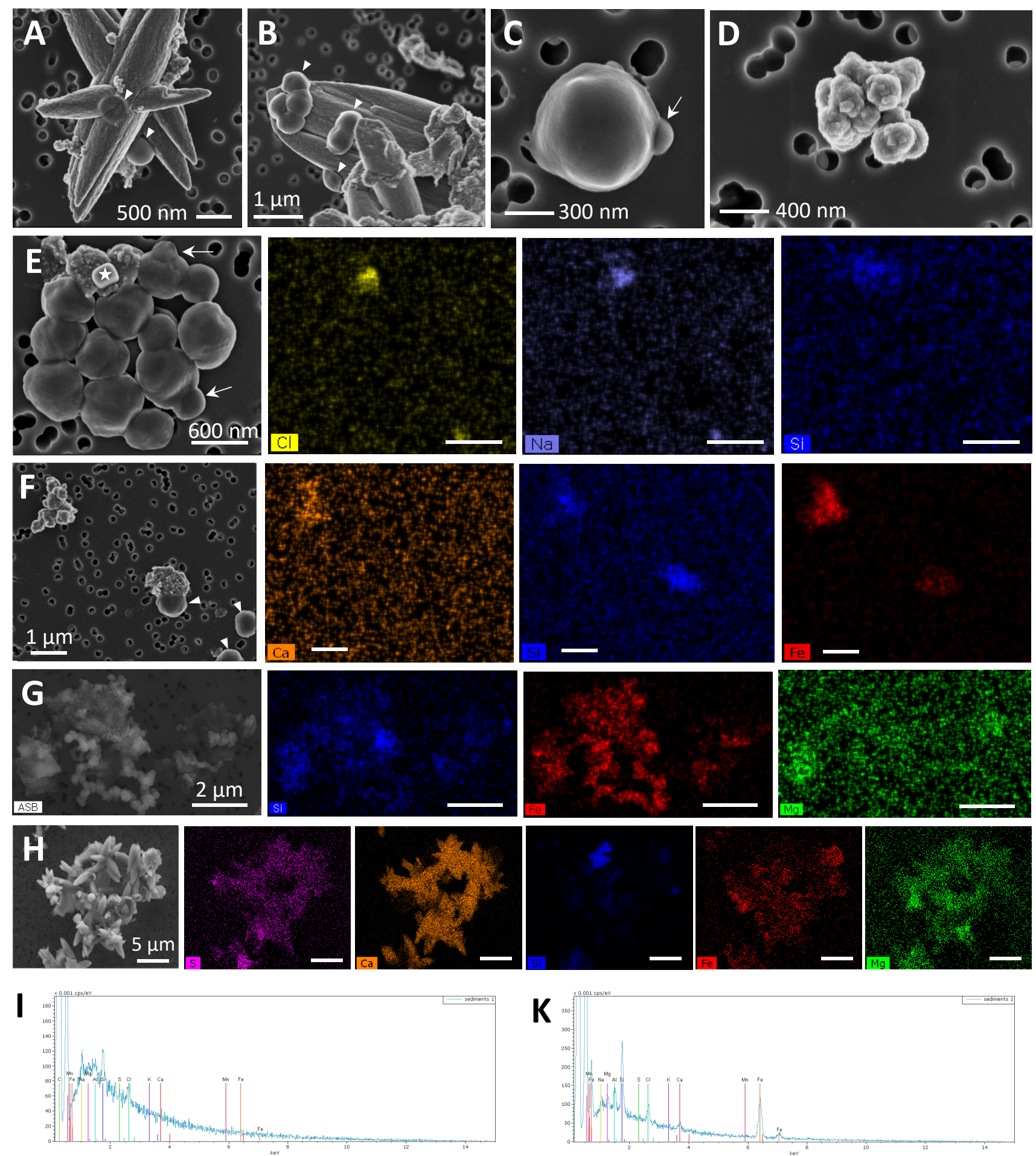

K
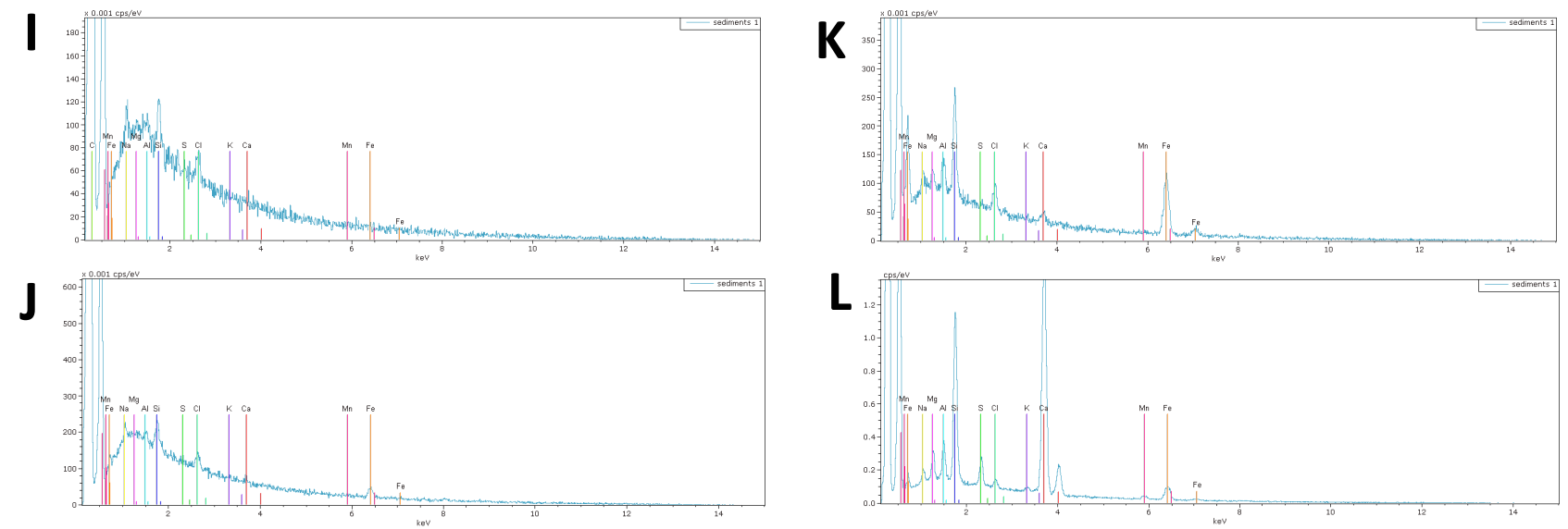

Fig.6. Belilla, Iniesto et al. 